\title{
The Estimation of Proteid in Small Quantities of Human Milk.
}

\author{
By Alfred W. Sikes, M.D., B.Sc. (Lond.), F.R.C.S., M.R.C.P., \\ Pathologist to Queen Charlotte's and the Samaritan Hospitals.
}

(From the Pathological Laboratory of Queen Charlotte's Hospital.)

I HAvE been for some months experimenting with a view to finding a quick and reliable method of estimating the amount of proteid in specimens of milk, usually from those cases where the children were not gaining, or getting on as well as might have been expected. The estimation of the fat is a comparatively easy process, but it is also necessary to know the percentage of proteid, as it is quite possible that an excess or deficiency of this constituent may upset the child. The amount of sugar present $I$ have found to vary so slightly that I do not consider the estimation of this substance of much importance.

In estimating the proteid in the usual way by means of first estimating the sugar, the fat, and ash, and then deducting from the total solids, the difficulty is that it requires a considerable amount of experience to get exact results; one requires a lot of apparatus; it takes up a great deal of one's time, and it requires a much larger sample of milk than in the method I will presently describe, and in many cases where the infant is not thriving, and the supply of milk small, one can only obtain a few cubic centimetres of milk.

Before reaching the process described below I tried all the wellknown precipitants of proteid, including phospho-tungstate, trichloracetic acid, etc.; I also endeavoured to estimate the proteid by precipitating, and comparing the colour produced by adding the reagents which give definite colours with proteids; but I did not succeed in arriving at any satisfactory conclusion. I also tried by centrifugalising the precipitates in graduated tubes, rotating for definite times, and at the same rate of rotation, but this was found to be unsatisfactory, as even with two exactly similar preparations rotated at the same time the amount of precipitate read off was different, as the density of the precipitate varied; even an extra shake while adding the reagent, or the addition of the precipitant in slightly different ways, making all the difference. With large quantities of milk it might have been possible to do something with this method, but it was quite impracticable with small amounts.

I next tried alcohol and ether, first precipitating with alcohol, centrifugalising, then washing the precipitate with ether, then again with alcohol, but this does not remove all the sugar, and the ether 
renders the proteid very firm, so that it is difficult to wash afterwards with alcohol.

I finally adopted the following process:-1cc. (or better 1 gramme) of the milk is put into the glass tube of a centrifugal machine, to this 14cc. of absolute alcohol is added and enough dilute acetic acid to render it faintly acid, it is then heated in a water bath till it begins to boil, then rapidly centrifugalised, the supernatant liquid (if it be not quite clear) poured off through a small, good filter paper (this filtrate, as it cools, gives a whitish deposit of fatty substances, and the solution contains nearly all the sugar); 14ce. of alcohol is again added, shaken up, boiled, centrifugalised, and the supernatant liquid filtered, if necessary, as before; this is then repeated a third time; finally any traces of proteid in the filter paper are washed off with some hot absolute alcohol, mixed with the precipitate, which is then transfered to a platinum capsule, evaporated over a water bath, dried at $100^{\circ} \mathrm{F}$., weighed, and the residue incinerated; the weight of capsule plus ash, deducted from the weight of capsule plus proteid, etc., gives the amount of proteid present in the quantity of milk taken.

In the above method the third filtrate does not give any colour with the xantho-proteic test, and does not give any reducing reaction with Fehling's solution; the second filtrate usually shows the presence of traces of sugar, and no trace of fat could be found in the washed precipitate. The use of boiling alcohol is absolutely necessary. In the above process all the usual precautions must be observed, such as never touching the capsule with the fingers, heating to redness before the capsule is used, and always allowing to cool in a dessicator.

In many cases it has been found that where the quantity of proteid was above the average the amount of fat was low, and this is perbaps what one would expect in poorly nourished mothers, assuming that fat is derived from proteid.

The following table gives the results obtained in 14 consecutive estimations from specimens taken between the 3rd and 12th days since confinement:-

\begin{tabular}{|c|c|c|c|c|}
\hline Date & & Confinement & & Per cent of proteid \\
\hline Oct. 6 & $\ldots \ldots$ & 3rd day & ...... & $1 \cdot 30 \%$ \\
\hline , 14 & $\ldots \ldots$ & 9 th & $\ldots \ldots$ & $1.50 \%$ \\
\hline 14 & $\ldots \ldots$ & 8th & $\ldots \ldots$ & $1.85 \%$ \\
\hline,$\quad 18$ & $\ldots \ldots$ & 12th & & $2 \cdot 15 \%$ \\
\hline,$\quad 18$ & $\ldots \ldots$ & 9 th & ...... & $2 \cdot 15 \%$ \\
\hline,$\quad 29$ & $\ldots \ldots$ & 4th & ...... & $1 \cdot 70 \%$ \\
\hline ,, 29 & $\ldots \ldots$ & 4 th , , & ...... & $180 \%$ \\
\hline
\end{tabular}


Date

$$
\begin{array}{cr}
\text { Nov. } 3 \\
, \quad 5 \\
, \quad & 5 \\
, \quad & 16 \\
\text { Dec. } & 30 \\
& 15
\end{array}
$$

Confinement

10th ,

7 th ,

5 th ,

9th ,

9th ",

8th ,"

5 th ,
Per cent of proteid

$\begin{array}{ll}\ldots \ldots & 1 \cdot 80 \% \\ \ldots \ldots & 2 \cdot 10 \% \\ \ldots \ldots & 2 \cdot 10 \% \\ \ldots \ldots & 2 \cdot 95 \% \\ \ldots \ldots & 1 \cdot 80 \% \\ \ldots \ldots & 1 \cdot 20 \% \\ \ldots . . & 1 \cdot 45 \%\end{array}$

The above results give an average of 1.84 per cent., they are not exactly accurate as the quantity of milk was lcc., but taking the sp.gr. of milk as 1,030 the corrected average comes out as 1.79 per cent., and the number usually accepted now is rather under 2 per cent. Since using the above for estimating the proteid of milk I find that it can also be used for estimating the proteid in the urine of renal cases. The estimation of the proteid by the above method takes less than an hour, and a good part of this time the precipitate in drying, so that the actual time employed in the process is small. One does not require much in the way of apparatus, as in all small laboratories there is a balance which will weigh to half a milligramme, a centrifugal machine, a water bath and a drying oven. 